\title{
LA LITERATURA POLICIAL DE SERGIO RAMÍREZ
}

\author{
ANDREA PezZè \\ Universidade de Coimbra \\ andreapezze@ces.uc.pt
}

RESUMEN: En este artículo reflexionamos sobre las modalidades escriturales del policial en la obra del nicaragüense Sergio Ramírez. En particular, nos proponemos cotejar dos tipologías del género, presentes en la obra de Ramírez y muy prolíficas en el panorama literario contemporáneo: la no-ficción y el neopolicial. La primera novela policial del nicaragüense, Castigo divino (1988), y algunos de sus últimos cuentos, son de la primera tipología, mientras que en 2008 publica una obra de la segunda. Apoyándonos en las teorizaciones sobre el género policial, y tras averiguar las diferencias fundamentales entre ellas, nuestro propósito es inferir cuales dinámicas del conocimiento enseñan las dos tipologías narrativas.

PALABRAS ClaVE: Sergio Ramírez; neopolicial; no-ficción; Centroamérica; géneros literarios

ABSTRACT: In this article, we ponder about the modalities of production of detective fiction in the Nicaraguan Sergio Ramírez's books. We pay specific attention

\footnotetext{
${ }^{1}$ Este artículo se produjo en el marco de una investigación desarrollada en el CES -Centro de Estudos Sociais- de la Universidad de Coimbra y financiada como beca post-doctoral por la FCT -Fundação para a Ciência e a Tecnologia- (referencia: SFRH/BPD/93975).
} 
to two typologies of genre, both used by Ramírez and prolific in the present literary landscape: no-fiction and . Ramirez's first detective fiction, Castigo divino(1988), and some of his last tales are about the first, whereas in 2008 he published a book about the second. Using theories about detective fiction in order to identify the main differences between them, our purpose is to infer which dynamics of knowledge these two typologies show.

KEYWORDS: Sergio Ramírez; Non Fiction; Center America; Literary Genres

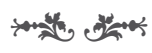

INTRODUCCIÓN

Nacido en Masatepe (Nicaragua) en 1942, Sergio Ramírez se gradúa en derecho en León en 1964. Desde 1977 encabeza el grupo de intelectuales, sacerdotes y dirigentes civiles conocido como Grupo de los doce; en 1979, tras el triunfo de la Revolución Sandinista, forma parte de la Junta de Gobierno, para llegar, en 1984, a ser Vicepresidente de la administración de Daniel Ortega. Antes de esa fecha, su labor para el Gobierno Sandinista ha tenido que ver con la producción cultural oficial, siendo presidente del Consejo Nacional de Educación y, en ámbito de divulgación y fomento de la cultura nacional, fundador de la editorial Nueva Nicaragua.

Sus primeras obras se publican a partir de los años 60 y en los 80 es, en Latinoamérica, autor conocido de ensayos y ficciones. Entre los primeros, citamos "Balcanes y volcanes" de 1973, incluido en la colección Centroamérica hoy dirigida por Edelberto Torre Rivas; ${ }^{2}$ por lo que atañe las obras de ficción, estas son de carácter muy diferente: Charles Atlas también muere (1976) es una colección de cuentos muy heterogéneos en la que el autor enseña su conocimiento, capacidad de manejo paródico y reescritura de las literaturas dichas populares, entre las cuales destacan la historieta y el género de espionaje; ¿Te dio miedo la sangre? (1977) es, en cambio, una novela de ambientación histórica en la que se incluyen las hazañas y la represión relacionadas con la insurgencia sandinista.

A partir de esta rápida introducción bio-bibliográfica, se arguye como Ramírez pertenezca a ese largo linaje de escritores latinoamericanos que han hecho del compromiso político una razón de escritura y, a través de ella, han definido el diagnóstico y el programa (Sarlo y Altamirano 1991: xv) de sus naciones. Muchas veces, dichos intelectuales, los letrados, llegaron a ser los administradores de los intereses de la nación: Domingo Faustino Sarmiento en Argentina, Rómulo Gallegos en Venezuela o Juan Bosch en la República Dominicana. Sin la necesaria constante de la posición político-ideológica, el escritor latinoamericano ha sido a menudo no solo politizado sino también un político.

\footnotetext{
2 Este primer trabajo de crítica de la cultura se publicará posteriormente en el volumen Balcanes y volcanes y otros ensayos (1985), por la Editorial Nueva América de Buenos Aires, convirtiéndose en uno de los textos fundamentales sobre cultura centroamericana contemporánea.
} 
Otro aspecto que hace encajar Ramírez en la tipología de escritores-políticos, es la tendencia a incluir o utilizar al mismo tiempo narraciones pertenecientes a la cultura dicha alta y otras más "populares". El pensamiento del nicaragüense se transmite a través de ensayos o novelas más conformes al canon de la literatura y a géneros de masas al estilo del folletín, del policial o de la novela de espionaje. Peculiaridad que comparte con muchos de los escritores-políticos. Pensemos en Domingo Faustino Sarmiento, uno de los iniciadores de este tipo de figura en Hispanoamérica. El libro fundamental de la argentinidad pos-independencia, (1848), es un cruce entre panfleto, ensayo histórico, manifiesto político, biografía y novela del oeste. Otro ejemplo podría ser Rómulo Gallegos, quien incluye, en su prosecución sucesiva del tropos cultural "Civilización o Barbarie", la copla y otras expresiones regionales venezolanas, en un afán de realismo costumbrista y retrato etnográfico.

Una cifra propia de la escritura del nicaragüense, que le otorga cierta originalidad dentro de este panorama, es el manejo de una variante del testimonio ${ }^{3}$ con rasgos peculiares: la no-ficción. Apoyándonos en los estudios sobre ella y reflexionando alrededor de sus características específicas, analizadas con cuidado por la argentina Ana María Amar Sánchez, trataremos de desentrañar el empleo, a lo largo de toda la trayectoria de Ramírez, del cruce de géneros entre policial y narrativas no ficcionales, por ejemplo el periodismo o el documentalismo. Por esta razón, llegaremos hasta una de sus últimas colecciones de cuentos, Flores oscuras (2013). Para completar el análisis del empleo de las diferentes expresiones del policial en el nicaragüense, nos detendremos también en El cielo llora por mí (2008), obra de corte más neopolicial que nos permitirá reflexionar sobre los límites narrativos y epistemológicos del género.

\section{CASTIGO DIVINO COMO PRECURSORA}

Para referirnos a las peculiaridades que la detective fiction cobra en la obra de Ramírez, necesitamos empezar un poco antes del comienzo de este siglo. Nos referimos a la publicación, en 1988, de la novela Castigo divino. En esta obra, que marca un hito importante en la literatura del Istmo por reintroducir, tras largas décadas de silencio, el policial en esas tradiciones narrativa, el lector se encuentra frente a la investigación posteriori de un acontecimiento criminal de 1932 - una serie de tres asesinatos por envenenamiento ocurridos en la ciudad de León-, del que es acusado un joven abogado guatemalteco, Oliverio Castañeda. Se señala que el delito común más relevante de la historia nicaragüense, ocurrió en la ciudad donde Sergio Ramírez cursó su carrera universitaria. De hecho, el juez Fiallos, entonces encargado del caso, fue, años después, profesor del

\footnotetext{
${ }^{3}$ Sergio Ramírez es también autor de testimonios más "clásicos", como por ejemplo el libro sobre su experiencia revolucionaria, Adiós Muchachos (1999), y, antecedente a esta, La marca del Zorro (1989), donde, en la más clásica tradición del testimonio centroamericanos (véase Miguel Mármol de Roque Dalton de 1982 o Me llamo Rigoberta Menchú... de la pareja Elizabeth Burgos/Rigoberta Menchú de 1983), el autor transcribe una larga conversación con Francisco Rivera Quintero (apodado "El zorro") que había fallecido el año anterior a la publicación de la obra.
} 
autor: "Yo solía introducir en las pláticas el caso Castañeda [...] que me interesaba antes de nada porque el voluminoso expediente podía leerse como una novela, y porque él era protagonista de esa novela" (Ramírez 1988: 417). Consideramos la circunstancia biográfica un detalle que nos dice algo sobre cómo se enteró Ramírez de algunos pormenores de la historia y de ahí se resolvió a escribir sobre ese acontecimiento. Pero, y el elemento es de nuestro interés, no nos dice por qué decidió contarlos justamente a través de la encrucijada narrativa entre ensayo histórico de corte académico, testimonio de los protagonistas del acontecimiento -por las numerosas deposiciones exhibidas a lo largo de la narración- y relato policial. En esta cita, el dato anecdótico nos interesa porque exhibe una estrategia narrativa apta a hacer coincidir el autor con el narrador que, en estas obras, también desempeña el papel de detective (que investiga los hechos reales a través de entrevistas, búsquedas de informaciones etc.). Si pensamos en dos ejemplos muy conocidos, el Francisco Freire de Walsh o las fortunas mediáticas del personaje Roberto (Saviano) en la obra de ambientación criminal Gomorra (2006), nos damos cuenta de que este trámite entre mundo real y literariedad es clave en la no-ficción. Freire o Roberto son personajes necesarios ya que no solo muestran las dinámicas reales de acceso a los documentos, sino que surgen a patrones éticos o morales del relato de los hechos.

Ricardo Piglia, en el ensayo "Sobre el género policial" contenido en Crítica y ficción (1986), escribe:

Son dos lógicas [la lógica del policial de enigma y la de la serie negra], puesta una a cada lado de los hechos. En el medio, entre la novela de enigma y la novela dura, está el relato periodístico, la página de crímenes, los hechos reales. Auden decía que el género policial había venido a compensar las deficiencias del género narrativo no ficcional (la noticia policial) que fundaba el conocimiento de la realidad en la pura narración de los hechos. Me parece una idea muy buena. Porque en un sentido Poe está en los dos lados: se repara de los hechos reales con el álgebra pura de la forma analítica y abre paso a la narración como reconstrucción y deducción, que construye la trama sobre las huellas vacías de lo real. La pura ficción, digamos, que trabaja la realidad como huella, como rastro, la sinécdoque criminal.(Piglia 2004: 60-61)

Castigo divino sondea un caso real $y$, al mismo tiempo, construye una estetización del acaecimiento. El primer aspecto se articula y se justifica a través de la exhibición de las fuentes de origen periodístico, el manejo de los partes judiciarios, las transcripciones de las deposiciones y de las cartas que los protagonistas se enviaron entre ellos. Es, por lo tanto, la narración de acontecimientos reales en la que a menudo son los mismos actantes -incluidos los periodistaslos que ofrecen los elementos narrativos de la historia:

Tanto por su referencialidad, que le confiere a la novela una dimensión histórica, como por el empleo de unos determinados recursos que producen la ilusión de estar ante una realidad objetiva, Castigo divino se apoya en el discurso histórico para edificar un mundo verosímil, en el que el lector tiene la posibi 
lidad de sentir que se encuentra ante la reproducción fiel de una determinada época de la historia nicaragüense. (Vargas 2003: 68)

Por otro lado, en Castigo divino el autor se vale de otros elementos narrativos que nacieron en los albores de la modernidad literaria decimonónica. El folletín puede ser un ejemplo. Por lo que atañe el cruce entre periodismo y novela por entrega, son de particular interés las técnicas de sujetivización de los personajes que, según Ana María Amar Sánchez, los sitúan "en el ámbito narrativo", al mismo tiempo "que siguen perteneciendo al mundo de "lo real»" (1992: 48). Un ejemplo sugerente depende de una (patente) falsificación que se articula a través de una galería de protagonistas de la cultura literaria latinoamericana que asoman en la obra, con un cuidado particular para el área centroamericana. La enumeración de los nombres sería larga y estéril. Nos limitamos a subrayar los más interesantes, empezando por Manolo Cuadra, el periodista que firma (ficticiamente) la mayoría de artículos (reales) sobre el caso, y que conocemos por ser, según algunos críticos, el autor que dio comienzo al testimonio en Nicaragua gracias a su Itinerario en Little Corn Island (1937). Así, los partes periodísticos pertenecen al mundo de lo real mientras que sus autores se ficcionalizan en nombres relevantes de la cultura nicaragüense y latinoamericana en general. La paradoja propia de esta técnica consiste en que la falsificación aumenta la autoridad de la nota de prensa y consecuentemente del archivo al cual la novela se refiere. Por ejemplo, en Castigo divino encontramos también a José Donoso, Ariel Dorfman y Miguel Barnet (quien propone a Oliverio Castañeda la escritura de un documental sobre Guatemala). ${ }^{4}$

En la primera escena se introduce también otro aspecto narratológico relevante en la no-ficción y que constituye el eje de este discurso: la interdependencia formal, en este caso con el policial. De hecho, la mayoría de los críticos que han estudiado Castigo divino, no dudan en definirla de policial a secas (último, solo en orden de tiempo, el artículo de Antonio Melis de 2013) o bien un cruce de géneros en el que el policial representa la herramienta fundamental. Esto porque la sintaxis narrativa que se despliega del comienzo al final se inscribe en las escrituras de detection y sirve para llenar los huecos cognoscitivos o las contradicciones que la verdad oficial no logra aclarar. Para relacionar entre ellos los elementos problemáticos y las hipótesis, ${ }^{5}$ y hacerlos consecuentes en términos cronológicos, lógicos y hermenéuticos, Ramírez emplea una dispositio dotada de estatuto epistemológico. A lo largo del siglo xx, el policial ha pasado de juguete literario (pasión oculta, divertissement, diversión excéntrica) a configurarse cual

\footnotetext{
${ }^{4}$ El escritor cubano es el intelectual latinoamericano que, con su Biografía de un Cimarrón de 1967, primero rubricó la literatura testimonial bajo este nombre para luego divulgarla gracias a entrevistas (Riccio 1990: 591-603) y sobre todo al ensayo La fuente viva (1983).

${ }^{5}$ Ezequiel del Rosso habla, con Roland Barthes, de hipertrofía del código hermenéutico: "Podríamos decir que un relato pertenece al género policial desde el momento en que presenta, por llamarla de alguna manera, una hipertrofía del código hermenéutico, tal como lo definió Roland Barthes: 'los diferentes términos (formales) a merced de los cuales se centra, se plantea, se formula, luego se retrasa y finalmente se descifra un enigma'. Por supuesto, Barthes está pensando en un rasgo que define a todo relato y no sólo a los policiales" (2002: 133).
} 
elemento fundamental de nuestra armazón lógica, y no solo en términos argumentativos, sino también desde un punto de vista formal.

Más en concreto, la interdependencia formal se da gracias a la estetización de elementos típicos de la detection y a las intertextualidades específicas del noir. ${ }^{6}$ Nos referimos, en el primer caso, a las expectativas creadas en el lector por parte del suspenso, fundamental en el thriller. Serían numerosos los ejemplos de anticipaciones catafóricas y prolépsis presentes en la obra. Muchas de estas tienen que ver con una reconstrucción de las deposiciones, en un claro efecto de manipulación de la cualidad de los testigos: "[lo] sabe, sin embargo, a la fecha de su declaración; pero, por motivos que ya serán de nuestro conocimiento, calla, mostrándose igualmente reluctante frente a otras preguntas del Juez relativas a su esposo" (1988, 72). Para el segundo nos conformamos con subrayar que el título de la novela se refiere a la película Payment deferred de 1932, dirigida por Lothar Mendes y traducida al español con el título de Castigo divino. Al comienzo de la novela, los protagonistas acuden con entusiasmo al estreno del filme y este establece de inmediato el marco cultural en el que se incluye la obra: primero por la relación entre el argumento de la película y la historia de Ramírez -ambas sobre asesinatos con estricnina-; segundo, y tal vez más importante, porque los patrones estéticos de la película se diluyen en la novela.

Tenemos una herramienta narrativa documental/testimonial y al mismo tiempo una dispositio ficcional que se articula entre folletín y género policial, en sus vertientes cinematográficas y literarias. Lo que nos interesa subrayar, es la manera en que la novela presenta dos versiones de los hechos $y$, por consiguiente, de la modernidad del conocimiento: la primera se organiza dentro del concepto de "verdad oficial" y depende del archivo autorizado sobre hechos reales, ${ }^{7}$ la segunda, además de estructurarse gracias a una herramienta argumentativa popular, se propone desarmar, desestructurar y desmentir la versión oficial.

En el contexto cultural latinoamericano la interdependencia entre práctica del periodismo o de la investigación historiográfica -colección de materiales documentales, análisis de los archivos-y la unión de estos elementos a través de las estructuras sintácticas del género policial, ha sido empleada numerosas veces, por la mayoría en contextos politizados de confutación de la versión oficial sobre los hechos. En algunas ocasiones, pensemos por ejemplo en Operación Masacre (1957) de Rodolfo Wash o en las obras de Poniatowska o Leñero, las investigaciones periodísticas, armadas sobre una herramienta policial, han re-

\footnotetext{
${ }^{6}$ De hecho, en la novela de Ramírez, las intertextualidades y las rupturas de las fronteras entre los géneros son numerosas. Gisela Kozak Rovero habla de una subversión del género policial y del folletín en general, ya que estas dos tipologías narrativas se interconectan con los materiales documentales para ponerlos en tela de juicio. En particular, los lenguajes que la novela trata de desenmascarar, son, siguiendo otra vez a Rovero: "a) las declaraciones en los juzgados [...]; b) el lenguaje oficial de las fuerzas policiales, en sus relaciones con la prensa y, consecuentemente, con la sociedad civil; c) el poder eclesiástico; d) las entrevistas y los reportajes periodísticos" (2001: 28-29).

7 Debido a la cercarnía de la primera modalidad con el periodismo, esta forma de contar hechos reales ha ido desarrollándose en los países anglosajones y en autores fundamentales como Truman Capote bajo el nombre de new periodism. Véase Albert Chillón, Literatura y periodismo (1999).
} 
presentado estrategias eficaces para recusar las verdades del Estado y, al mismo tiempo, se han configurado como paradigma moral, político, histórico y literario de una etapa fundamental para la historia de una nación (Argentina o México), un movimiento político (peronismo o el 68), un área literaria. En muchos de estos textos se señala otra actitud interesante (que resulta menos enfatizada en Castigo divino): la extensión del texto fuera de sí mismo, en búsqueda de una fuerza pragmática suficiente para que el lector no solo se convenza de la versión contra-hegemónica, sino que actúe de la forma política y moral que el libro propone o presupone. ${ }^{8}$

\section{ENTRE PARÉNTESIS: EL CIELO LLORA POR MÍ}

La producción de Sergio Ramírez prevé también una novela de corte neopolicial, añadiendo su nombre al largo listado de autores latinoamericanos en general y centroamericanos en particular (pensamos en Dante Liano con El misterio de Montserrat de 1994 o Rodrigo Rey Rosa con Los sordos de 2012) que han empleado el género para sondar la realidad de la violencia política de finales del siglo xx. En El cielo llora por mí (2008) la investigación se desencadena tras el descubrimiento de un yate abandonado en la bahía de Pearl Lagoon, en el sur de la costa oriental de Nicaragua. Este hallazgo remite de inmediato al tráfico de narcóticos desde Colombia hasta el cartel de Sinaloa, México. Siendo Nicaragua un lugar de tránsito, la novela se fija más en las relaciones de corrupción y coerción de la criminalidad y de la política relacionada con este negocio que en el fenómeno per se. Por otro lado, su filiación neopolicial simplifica el análisis temático ya que no se aleja de los patrones más comunes del género, aspecto este que desató algunas críticas hacia su autor y que nos interesa aquí profundizar. Esencialmente, se le acusó a Ramírez de comercialización y desvirtuación del compromiso social que siempre había demostrado a través de su literatura. Uriel Quesada, en su artículo "De Castigo divino a El cielo llora por mí: veinte años de neo-policiaco centroamericano", nos ofrece la opinión del importante crítico guatemalteco Arturo Arias quién opina que en Ramírez (y Gioconda Belli) hallamos la "[pérdida de] ese papel transgresivo que jugó la textualidad durante el período guerrillerista, [que] ha cedido a una producción que se amolda más a los parámetros del entretenimiento transnacional" (2012: 71).

¿Por qué esta crítica tan contundente? Es verdad que sea Belli el autor objeto de estas páginas ablandaron su compromiso literario a favor de una redefinición del papel ideológico del escritor, cuestionando los alcances reales de la Revolución Sandinista; es también verdad que en la posmodernidad -que es-

\footnotetext{
${ }^{8}$ Si bien este aspecto no es muy relevante en Ramírez, sí lo es en el testimonio centroamericano que se articula al mismo tiempo sobre la épica y la picaresca: de ésta tiene la narración de la biografía desde la infancia (cfr: Rigoberta Menchú, Miguel Mármol, Omar Cabezas etc.), de la épica reproduce la voluntad de hacer del testigo un ejemplo y un sujeto colectivo. Hay que decir que si, por ejemplo, Poniatowska o Walsh escribían en función de (o auspicando a) una toma colectiva de conciencia que fomentara un cambio social revolucionario o reformista, en 1988 Ramírez vivía ese cambio, por el que él mismo había luchado.
} 
tas obras, de alguna forma, reproducen- existe una voluntad de reformulación de los esquemas ideológicos de la izquierda revolucionaria. Sin embargo, a pesar de avalar masivamente el fin de las ideologías, nuestro pensamiento "post" queda anclado en las leyes capitalistas de la plusvalía y de la explotación de la mano de obra que finalmente producen las monstruosidades del capitalismo tardío en América Latina (narcotráfico, violencia de género etc.) y en los demás países poscoloniales.

En la novela de Ramírez nos encontramos frente a la exhibición de la vivencia del pensamiento machista también dentro de los paradigmas sandinistas. El cielo llora por mí pondría en escena, de forma involuntaria o menos, un límite del discurso revolucionario, relativo a la discriminación de género.

Para reflexionar sobre el caso, traemos a colación el ensayo de Doris Wieser "Masculinidad y violencia de género en la novela negrocriminal nicaragüense". La autora se fija en tres novelas nicaragüenses recientes, entre las cuales incluye El cielo llora por mí (las otras dos son Managua Salsa City de Franz Galich, de 2000, y La muerte de Acuario de Arquímedes González, de 2002). La intención de la autora no es la de detectar una supuesta tara nicaragüense (el machismo) sino señalar al lector la persistencia de esta característica también en la producción cultural del país centroamericano.

En realidad, un carácter constante del policial, y en particular de la serie negra, es el molde con el que dibuja el detective: un superhombre de masas, muy a menudo misógino ${ }^{9}$. En El cielo llora por mí las actuaciones machistas son del detective, un ex-sandinista cuyo nombre (programático) es Dolores Morales. Representan, por lo tanto, una crítica a uno de los límites intrínsecos a la Revolución, subrayado, entre otros, también por la Gioconda Belli de El país bajo mi piel (2001). ${ }^{10}$

De ser así, no habría por qué reflexionar sobre El cielo llora por mí. El problema estriba en otro elemento: la investigadora alemana nos hace notar que el narrador no toma ninguna distancia de las opiniones y actuaciones del protagonista, hasta casi justificar una probable violación sexual:

Las voces del narrador y de los personajes suelen superponerse (pensemos en la polifonía de Bajtín) y es difícil discernir la una de la otra. Esto ocurre cuando hay dudas de si se trata de un discurso indirecto libre o del relato del narrador

\footnotetext{
9 También la citada Operación Masacre de Walsh, cuyo objetivo es una firme voluntad moral y política de justicia, no se abstiene de esa caracterización del detective. Lejos de querer inferir una misoginia en Walsh sin los necesarios instrumentos críticos, es verdad que él también caracteriza su detective a través de su aislamiento e individualismo: "Desde el principio está conmigo una muchacha que es periodista, se llama Enriqueta Múñiz, se juega entera. [...] Simplemente quiero decir que en algún lugar de este libro escribo «hice», «fui», «descubrí», debe entenderse «hicimos», «fuimos», «descubrimos»" (2004: 21).

10 Doris Wieser se apoya en el ensayo de Andrea Goosses "La tierra gira masculinamente, compañero. El ideal de masculinidad del guerrillero" (2001) que se centra en La montaña es algo más que una inmensa estepa verde (1982) de Omar Cabezas. Así concluye Wieser: "Es una imagen heroica del hombre nuevo socialista-sandinista como combatiente intrépido. Sin embargo, en términos retóricos se trata de una paradoja porque esta imagen combina lo supuestamente 'nuevo' con un concepto de masculinidad totalmente tradicional" (2015: 212).
} 
omnisciente. [...] Por lo tanto, no se sabe si el comentario sexista y machista "las nalgas y los pechos rebosantes" [cita de la novela, p. 14] de la inspectora, caracteriza al inspector Morales o si se trata de la mirada del narrador, estrechamente ligada a la del autor implícito. Este mecanismo lo encontramos en toda la novela, que se vuelve, en consecuencia, ambigua en relación con cuestiones de machismo, misoginia, homofobia e incluso violencia de género. Como lectores no sabemos en qué medida el narrador (y por extrapolación el autor) concuerda con los pensamientos y el comportamiento políticamente incorrectos de los personajes. (Wieser 2015: 221)

Primero, queremos discutir la concordancia entre narrador y autor. Si es verdad que tenemos la tentación de relacionar el narrador omnisciente heterodiegético con el autor, también es verdad que no sería formalmente correcto darlo por sentado: muy bien podría ser un ciudadano corriente (así como lo es, a bien mirar, Dolores Morales), representante de una actitud estereotipada frente al acto de narrar. Otra consideración de orden literario tiene que ver con la tradición del género: el narrador, a menudo homodiegético, es el detective o un personaje cercano a él (el clásico ayudante). De otra forma, la excentricidad propia del protagonista, su lejanía con el discurso oficial del Estado (también cuando le pertenece, siendo un policía), su empecinamiento en perseguir una justicia imposible en el mundo de los privilegios burgueses, terminarían siendo rasgos contundentes de antisocialidad, depravación o locura. Dolores Morales y "su" narrador tienen el mismo privilegio a pesar de la distancia narrativa que mide entre los dos: como bien escribe Wieser, comparten la posición del punto de vista que, por lo tanto, pasa constantemente de lo particular (la mirada individual del detective) a lo general (la figura social de un autor o de un ser omnisciente).

Sin entrar en cuestiones relativas a la sociología de la literatura, queremos añadir otro elemento de orden narrativo que nos parece importante para esta larga digresión sobre la pareja narrador/detective y ayudarnos a entender qué es lo que, desde nuestro punto de vista, la novela de Ramírez enseña. El enfoque centrado en el detective o en alguien cercano a él, hace que el criterio de verdad y de moralidad o ética, dependa únicamente del conocimiento del detective mismo, quien se configura como el único intérprete de la realidad. Ricardo Piglia, en una nota sobre el hard boiled norteamericano, escribe: "en la novela negra norteamericana parece no haber otro criterio de verdad que la experiencia: el investigador se lanza, ciegamente, al encuentro de los hechos, se deja llevar por los acontecimientos y su investigación produce, fatalmente, nuevos crímenes" (2003: 80). Añadimos que dichos crímenes pueden producirse también por mano del detective mismo. De hecho, la gran mayoría de los héroes de la novela negra puede ser criticada desde un punto de vista político o moral. En el mismo artículo (y también en otro incluido en Crítica y ficción), Piglia aclara que en el hard boiled el planteamiento básico de la injusticia social tiene que ver con la relación capitalista entre el dinero y la ley. Con buena probabilidad, esta visión de rasgos marxistas depende de la gran narración en la que el policial histórica y socialmente se inscribe. Dashiel Hammett, primer gran autor del hard boiled, tuvo reiterados problemas con los gobiernos de Estados Unidos de la segunda mitad del 
siglo XX por ser lector de los clásicos del materialismo dialéctico (Barros Lémez 1986). Entonces, si hoy la crítica al marxismo apunta a los límites epistémicos de éste (su reducción, por ejemplo, del problema de género a una cuestión de clases), también en la novela policiaca dichos límites se hacen evidentes: Sam Spade o Philip Marlowe son dueños de una rectitud moral que justifica su lenguaje y su conducta. Los dos no presentan contradicciones ya que ellos mismos son narradores de sus hazañas. En cambio, si el albedrío del detective responde a las dinámicas del pensamiento débil del fin de la modernidad (tanto en su teorización como en la desestructuración de las metanarrativas), ${ }_{1}^{11}$ puede resultar ambiguo o no centrado en una grande narración que justifique in toto su juicio, su raciocinio y su conciencia. Tal es el caso que nos interesa. Desde un punto de vista narratológico, en el neopolicial se representan -también involuntariamente y por razones muy diferentes- los paradigmas de la modernidad, desestabilizados inevitablemente por sus contradicciones internas. Por supuesto, en el caso de $E l$ cielo llora por mí, los límites coinciden con las faltas del sandinismo en términos de justicia de género, pero no son explícitos sino que se acentúan en la peculiar relación de complicidad entre protagonista y narrador que involuntariamente reitera, enfatizándolas, las culpas o los fallos de Dolores Morales.

Estas razones nos permiten decir que Doris Wieser acierta cuando subraya la ambigüedad del narrador, aunque añadimos que nos parece más la reelaboración de un tropos que una manifiesta misoginia del autor. El problema, más que una acusación privada dirigida a Ramírez, podría constituirse en el momento en que consideramos la literatura no solo en términos de representación de una realidad histórico-social, sino también en términos de instrumento de creación de una sociedad. Dolores Morales, tal y como la mayoría de los detectives y a pesar de sus defectos (cuyo elemento simbólico es la cojera), encuentra la simpatía de los lectores por su sentido de justicia. Por esta razón, los comentarios, respaldados por el narrador, pueden ocasionar la perpetuación del modelo machista y sus secuelas negativas. Aquí, teóricamente, entra en escena el trabajo del crítico, quien esboza una propuesta de lectura: la novela apunta a las contradicciones del capitalismo (enfatizadas gracias a la mise-en-scène de un problema actual y contundente, el narcotráfico) a través de un prisma limitado de crítica social. En otras palabras, el detective no logra solucionar problemas estructurales (en sentido marxista) porque no tiene el poder político y económico para hacerlo; no puede enderezar, y hasta perpetra, crímenes sociales porque sus límites socio-culturales -espejos de su formación política- se lo impiden. Es evidente, entonces, que la justicia social no es una cuestión de manualística del cambio social; es un alcance cuya complejidad es mucho más articulada y aún por definir.

${ }^{11}$ Cfr. Gianni Vattimo, La fine della modernità (1985) y con Pier Aldo Rovatti, Il pensiero debole (1983). 


\section{De Castigo divino a Flores oscuras}

Antes de seguir con la presencia de la no-ficción en unos cuentos de Flores oscuras, queremos apuntar a otros ejemplos de ruptura de los límites entre periodismo y géneros populares. En la colección de cuentos Catalina y Catalina (2001), las interdependencias formales son muy interesantes: "La herencia del bohemio" es un divertissement en el que periodismo, testimonio y policial tratan de establecer la propiedad jurídica de una "Gigantona", una muñeca del folclore nicaragüense; "La partida de caza" es una ficción paranoica -igual que otro cuento de la misma colección, "Gran Hotel"- en la que el policial sirve para desentrañar un complot armado contra un jugador de Alemania Oriental, Lutz Eigendorf, quien se fugó a occidente y que murió tras un misterioso accidente de tránsito. En otra colección de cuentos, El reino animal (2006), la nota periodística se acompaña al típico bestiario.

Volviendo a Flores oscuras, notamos que ya el cuarto de la serie presenta una historia policial. "Ya no estás más a mi lado corazón" cuenta las investigaciones que se producen tras el asesinato de una artista del circo apodada "la sin par Mireya". El cuento no se basa en hechos directamente identificables como reales, pero hace dialogar el tono picaresco del testigo principal -y narrador del cuento- con el lenguaje técnico de los informes judiciales y las transcripciones de los interrogatorios. El lenguaje vive, por consiguiente, dos funciones diferentes según nos encontremos en los lugares prestados a la historia oficial o a la sabiduría popular. El narrador es un chico de once años testigo del crimen por haber accedido a los favores sexuales -bajo emolumento- que la "sin par Mireya" ofrecía, después de trabajar de trapecista, amazonas, repartidoras de boletos y personal de limpieza, siendo su marido, el Tragafuego Luzbel consciente de esta actividad. Por supuesto, este detalle de que un chico aún no adolescente acuda a prestaciones eróticas comerciales, proporciona cierta exaltación nerviosa en la familia de él: "noticia que provocó el llanto y las lamentaciones de mi madre que no paraba en su extremo estado de histeria de acusarme de niño perverso y corrompido, mientras mi padre [...] quiso cuerearme con su cinturón de braqueta" $(2013,504) .{ }^{12}$ La misma circunstancia es narrada así en la oficina del juez: "[...] solicitando mi padre desde la puerta, ya más calmado y repuesto el cinturón en sus pantalones, que se hiciera constar que era yo menor de edad e hijo de dominio, lo cual así se hizo, aunque el juez advirtió a mi padre, sin que fuera materia del acta, que poco dominio y potestad demostraba conmigo [...]" (Íbid., 529).

Las interpretaciones sobre la verdad sufren la misma doblez: por un lado, tenemos la vertiente lingüística oficial según la cual el culpable es el matrimonio de la occisa, por lo lógico que pueda parecer la idea de que una persona le tenga celos a una mujer que trabaja de prostituta; por otro, se nos presenta la figura barroca del enano Leonardo el Galante quien declara haber matado a Mireya tras el último rechazo de ella. Leonardo es descartado de los testigos y en medio de la vía pública, actúa de manera desaforada para demostrar su culpabilidad.

12 El número se refiere a la posición del ebook (Alfaguara, 2013). 
La escena es, en general, pintada con matices grotescos y surreales. El cuento termina con un detalle sobre el Galante que hace dudar de la solución oficial del crimen. El policial, en este caso, más que ser una construcción de la historia, es una modalidad de lectura. Diría Borges en el cuento "Examen de la obra de Herbert Quain", "[e]l lector, inquieto, revisa los capítulos pertinentes y descubre solución, que es la verdadera. El lector de ese libro es más perspicaz que el detective" (2004: 79), o, en este caso, que el juez.

Sin embargo en otros dos cuentos de Flores oscuras la relación entre policial, testimonio y periodismo cobra mayor interés para nuestro discurso: "Las alas de la gloria" y "Abbott y Costello".

"Las alas de la gloria" fija su filiación desde el comienzo: "La madrugada del miércoles 21 de abril del año 2004, un adolescente de nombre desconocido mató de diez estocadas de bayoneta en el barrio Monibó, en la ciudad de Masaya, a José Trinidad Aranda Calero, de cincuenta y cinco años de edad. Quedó demostrado en las pesquisa policiales que el arma era de propiedad de la víctima" (2013: 687). Además de este arranque, el narrador declara que la entera construcción de "Las alas de la gloria" depende de fuentes supuestamente periodísticas: "He guardado por años las notas del suceso, publicadas en los diarios de Managua, La prensa y, El Nuevo Diario bastantes similares porque están basadas, sobre todo, en las declaraciones de la vocera policial" (2013: 729).

El asunto que el policial se propone investigar $-y$ del que se desprende otra historia- es la razón por la cual ocurrió este hecho delictuoso. Resulta que los dos se habían sentado en la acera frente a un almacén para seguir bebiendo alcohólicos a pesar de que este hubiera cerrado. En un momento se produjo un alterco y de ahí la víctima amenazó al adolescente con su bayoneta para luego perderla y terminar asesinado. La razón por la que pelearon depende de una acusación que la víctima le hizo al asesino: en palabras de ellos, y como nos hace saber la vocera policial, la cuestión era sobre "quién tenía más huevos". El problema que se pone el narrador, y que desencadena la investigación policial, tiene que ver con la razón por la cual una persona (José Trinidad) decide altercar sobre esta duda hasta amenazar de muerte a su interlocutor. Para entenderlo, por lo tanto, se necesita un trabajo policial que inevitablemente termina o en la psicología o en la biografía del occiso (o en ambas). Inferir las razones biográficas que hayan proporcionado tan alto nivel de resentimiento es la tarea del detective/narrador: "[p]ero en el camino nos surge otro dato que debemos tomar en cuenta, y que el lector no despreciará. También lo llamaban «el Comandante». Tres apodos para una sola persona pueden parecer excesivos. «El Panadero», «el Chirizo», «el Comandante»" (2013: 719). El primero, depende de su humilde trabajo de repartidor de pan en Managua, el segundo de su pelo rebelde al peine y el tercero nos permite descubrir su identidad juvenil de guerrillero. El hombre en el cruce de caminos: para remontar a la biografía se necesita, por lo tanto, de una investigación. Esta parte no-ficcional del cuento se diferencia del testimonio a secas por las modalidades con las que se reconstruye la biografía (la pesquisa contra la entrevista, típica del segundo) y también por las intenciones pragmáticas que la narración implica. La diferencia fundamental es de movimiento. Sea 
en la escritura testimonial sea en su variante no-ficcional, la narración se dirige hacia adelante, en perspectiva: porque la biografía se cuenta desde el comienzo y porque el lector, atrapado por las hazañas del héroe popular cuya historia se relata, decide cambiar su visión del mundo y posiblemente su quehacer para juntarse a la agrupación que el protagonista representa. En el caso de "Las alas de la gloria", la biografía y el análisis político son retrospectivos. La primera parte del fracaso y la muerte para remontar a la gloriosa épica del guerrillero, pasando por el desencanto de la desmovilización post-sandinista. Entonces, se desestructura la leyenda de un pasado fundacional, presentando al lector otro punto de vista sobre la guerrilla y sobre los olvidados que -a pesar de sus condiciones actuales- en ella forjaron su identidad. El desafío de José Trinidad al joven representa simbólicamente el mito que se desmorona frente al contexto.

Dejemos establecido que el adolescente ignoraba quien era José Trinidad [...]. Y aun si José Trinidad hubiera intentado explicarle su pasado, y hacerle alarde de la más intrépida de sus hazañas, el adolescente a lo mejor no le hubiera entendido, o no le hubiera creído, y en último caso tampoco le hubiera importado. (Ramírez 2013: 750)

"Las alas de la gloria" es un cuento en el que la no-ficción y su enlace entre periodismo y policial se mueven hacia la re-definición de un pasado más en términos de diagnóstico que de propuesta.

Finalmente, nos fijamos en el cuento "Abbott y Costello" que, de la misma manera que el antecedente, empieza con una nota periodística: "Natividad Canda Mairena, de veinticinco años de edad, murió la madrugada del jueves 10 de noviembre del año 2005 destrozado por dos perros rottweiler que lo atacaron a mordiscos" (2013: 1757). En el cuento se narra el proceso judicial que empieza tras el funesto acontecimiento. Tenemos que decir que el occiso era un nicaragüense emigrado a Costa Rica y que se había introducido en el taller de unos burgueses para robar, siendo atacado por dos perros (Abbott y Costello) sin que los policías de vigilancia ni los dueños de la vivienda hicieran nada para detener los sabuesos o prestar auxilio a la víctima. Llama la atención la división en párrafo que el autor elige (y que recuerda a Operación Masacre de Walsh): ${ }^{13}$ se empieza con "Los hechos", donde la narración sondea las notas de prensa que se ocuparon del caso; luego tenemos "El occiso", "El shock ipovolémico" y "Los perros", donde asistimos al proceso de subjetivización de los protagonistas, sobre todo la víctima; finalmente tenemos "Reconstrucción de los hechos" y "La sentencia judicial", donde el lenguaje es oficial y prevé la colección de evidencias que llevan a eximir de los cargos penales a todos los acusados de omisión de socorro. En estos dos párrafos se introduce también la interdependencia con el policial para desmentir las verdades oficiales y, al mismo tiempo, reconstruir otra. Es el cuento más parecido a Castigo Divino puesto que la no-ficciónse propone un objetivo pragmático claro: inferir moralmente sobre la justicia burguesa

13 En Operación Masacre, la división en partes es la siguiente: "Las personas", "Los hechos", "La evidencia". 
$y$, en este caso, racista. Por lo tanto, el párrafo final es otra vez una nota narrativa sobre la víctima con el intento de devolverle la dignidad, aunque póstuma. La ficción se hace cargo de llenar los huecos cognoscitivos -voluntarios, políticos, de autodeterminación del poder, de la falacia de nuestro conocimiento- que la verdad oficial deja en su camino. Un resumen del parte judicial que Ramírez se preocupa desmontar a través de la narrativización policial de los hechos y de la sentencia. Movimiento, en este caso, sí perspectivo: la voluntad pragmática del cuento se dirige al lector y le pide asumir conciencia de las deformidades que un sistema de justicia y de paz social produce.

\section{CONCLUSIÓN}

Sergio Ramírez es un escritor muy prolífico y nos hemos fijados solo en una parte de su obra que responde a determinadas características. Como hemos tratado de explicar, una razón de interés que ofrece en el panorama centroamericano, depende básicamente de dos cuestiones: por un lado, el papel que el autor de Flores oscuras representa en la prosecución y el desarrollo del testimonio literario, particularmente fructuoso en el Istmo; por otro, y con fuerte conexiones con el primer punto, el trabajo interesante que hace con el género policial, el cual nace (o renace) en Centroamérica a partir de la publicación de Castigo divino. Teniendo en cuenta la difusión popular del testimonio y la tardía difusión del policial, la elección de Ramírez de introducir el policial a través de un género reconocido y leído o, que es simétrico, renovar el testimonio gracias a la interdependencia formal con el policial, parece casi una tarea necesaria de desenvolvimiento de una tradición cultural y de sus caracteres peculiares. El paréntesis neopolicial de El cielo llora por mí puede despertar en el lector atento una duda importante: ¿queremos decir acaso que la no-ficción propone un nivel de veracidad más elevado? La respuesta es negativa: lo único que nos interesa proponer es una reflexión sobre cómo se articula el concepto de verdad en diferentes manifestaciones (o subgéneros) del policial. La serie negra o el hard boiled pretenden parecer realistas pero, a bien mirar, son artificios narrativos construidos alrededor de una visión idealista de la realidad. La no-ficción puede ser considerada, en cambio, la tipología literaria en la que se enseñan el proceso y la metodología que llevan al conocimiento. Se trata, por lo tanto, de establecer el papel ficcional del género, pero subrayando su capacidad de configurarse cual instrumento fundamental de la verdad en nuestra modernidad. Simetrías literarias, entonces, según las cuales una historia ficcionalizada se impone como real o una historia real se articula a través de una herramienta narrativa claramente ficcional. 


\section{OBRAS CITADAS}

Amar Sánchez, Ana María (1992): El relato de los hechos. Rodolfo Walsh, testimonio y escritura. Rosario, Beatriz Viterbo.

Barnet, Miguel (1980): Biografía de un cimarrón. La Habana, Letras Cubanas.

(1983): La fuente viva. La Habana, Letras Cubanas.

Barros Lémez, Álvaro (1986): Abraxas en el país de las pesadillas. La narrativa de Samuel Dashiell Hammett. Montevideo, Monte Sexto.

Borges, Jorge Luis (2004): Ficciones. Madrid, Alianza.

Chillón, Albert (1999): Literatura y periodismo: una tradición de relaciones promiscuas. Barcelona, Universitat Autònoma de Barcelona, Universitat Jaume I, Universitat de València.

Del Rosso, Ezequiel (2002): "Una lectura conjetural. Roberto Bolaño y el relato policial". En Celina Manzoni (ed.): Roberto Bolaño: la escritura como tauromaquía. Buenos Aires, Corregidor, pp. 133-144

Melis, Antonio (2013): "Crimen y política en una novela nicaragüense contemporánea". En Sabrina Costanzo y Domenico Antonio Cusato (eds.): La narrativizzazione del crimine nelle tradizioni letterarie spagnola e ispano-americana. Catania, Andrea Lippolis.

Kozak Rovero, Gisela (2001): "Castigo divino, de Sergio Ramírez novela policial, folletinesca, satírica y autorreflexiva", Iberoamericana, vol. i, n. ${ }^{\circ} 2$, pp. 27-41.

Piglia, Ricardo (2001): Crítica y ficción. Barcelona, Anagrama.

— (2003):"Lonegro del policial". En Daniel Link (ed.): Eljuego delos cautos. Buenos Aires, Dela Flor, pp. 78-83.

Quesada, Uriel (2012): "De a : 20 años del Neopolicial centroamericano". En Brigitte Andriaensen y Valeria Grinberg Plá (eds.): Narrativas del crimen en América Latina. Transformaciones y transculturaciones del policial. Berlín, LIT, pp. 59-74.

Ramírez, Sergio (1983): ¿Te dio miedo la sangre?. Barcelona, Argos Vergara.

- (1985): Balcanes y volcanes y otros ensayos y trabajos. Buenos Aires, Nueva América.

- (1988): Castigo divino. Managua, Nueva Nicaragua.

- (2001): Catalina y Catalina. Madrid, Alfaguara.

— (2006): El reino animal. Madrid, Alfaguara.

— (2007): Charles Atlas también muere. Buenos Aires, El Andariego.

- (2008): El cielo llora por mí. México, Alfaguara.

— (2013): Flores oscuras. México, Alfaguara.

Riccio, Alessandra (1990): "Miguel Barnet y el pacto testimonial", Annali dell'Istituto Universitario Orientale, vol. xxxii, n. ${ }^{\circ} 2$, pp. 592-603.

Sarlo, Beatriz, y Altamirano, Carlos (1991): "Introducción". En Esteban Echeverría: Obras escogidas. Caracas, Biblioteca Ayacucho, pp. vii-liii.

Saviano, Roberto (2006): Gomorra. Milán, Mondadori.

Vargas Vargas, José Ángel (2003): "Castigo divino: interdiscursividad y efecto paródico", Revista Comunicación, vol. 12, n. ${ }^{\circ} 1-2$, pp. 64-90.

Vattimo, Gianni (1985): La fine della modernità. Milán, Garzanti.

Vattimo, Gianni, y Rovatti, Pier Aldo (eds.) (2010): Il pensiero debole. Milán, Feltrinelli.

Walsh, Rodolfo J. (2003): Operación masacre. Buenos Aires, De la Flor. 
Andrea Pezzè

Wieser, Doris (2015): "Masculinidad y violencia de género en la novela negrocriminal nicaragüense", Badebec, vol. 4, n. ${ }^{\circ}$, pp. 205-232.

124 Pasavento. Revista de Estudios Hispánicos, vol. IV, n. ${ }^{1} 1$ (invierno 2016), pp. 109-124, ISSN: 2255-4505 